\title{
An epidemiological evaluation of pediatric long bone fractures - a retrospective cohort study of 2716 patients from two Swiss tertiary pediatric hospitals
}

Alexander Joeris ${ }^{1,2^{*}}$, Nicolas Lutz ${ }^{3}$ Bárbara Wicki ${ }^{2}$, Theddy Slongo ${ }^{1}$ and Laurent Audigée 2,4

\begin{abstract}
Background: Children and adolescents are at high risk of sustaining fractures during growth. Therefore, epidemiological assessment is crucial for fracture prevention. The AO Comprehensive Injury Automatic Classifier (AO COIAC) was used to evaluate epidemiological data of pediatric long bone fractures in a large cohort.
\end{abstract}

Methods: Data from children and adolescents with long bone fractures sustained between 2009 and 2011, treated at either of two tertiary pediatric surgery hospitals in Switzerland, were retrospectively collected. Fractures were classified according to the AO Pediatric Comprehensive Classification of Long Bone Fractures (PCCF).

Age, sex, BMI, injury and treatment data were recorded. Children were classified into four age classes and five BMI classes were applied. Seven major accident categories were established. Study parameters were tabulated using standard descriptive statistics. The relationship of categorical variables was tested using the chi-square test. The Children's BMI was compared to WHO reference data and Swiss population data.

Results: For a total of 2716 patients (60\% boys), 2807 accidents with 2840 long bone fractures (59\% radius/ulna; 21\% humerus; 15\% tibia/fibula; 5\% femur) were documented. Children's mean age (SD) was 8.2 (4.0) years (6\% infants; 26\% preschool children; $40 \%$ school children; $28 \%$ adolescents). Adolescent boys sustained more fractures than girls ( $p<0.001)$. The leading cause of fractures was falls (27\%), followed by accidents occurring during leisure activities (25\%), at home (14\%), on playgrounds (11\%), and traffic (11\%) and school accidents (8\%). There was boy predominance for all accident types except for playground and at home accidents. The distribution of accident types differed according to age classes $(p<0.001)$. Twenty-six percent of patients were classed as overweight or obese - higher than data published by the WHO for the corresponding ages - with a higher proportion of overweight and obese boys than in the Swiss population $(p<0.0001)$.

Conclusion: Overall, differences in the fracture distribution were sex and age related. Overweight and obese patients seemed to be at increased risk of sustaining fractures. Our data give valuable input into future development of prevention strategies. The AO PCCF proved to be useful in epidemiological reporting and analysis of pediatric long bone fractures.

Keywords: Pediatric, Long bone fracture, Classification, Epidemiology, AO COIAC

\footnotetext{
* Correspondence: alexander.joeris@aofoundation.org

'Department of Pediatric Surgery, Traumatology and Orthopedics, University

Hospital (Inselspital) Bern, Freiburgstrasse 15, 3010 Bern, Switzerland

${ }^{2} \mathrm{AO}$ Clinical Investigation and Documentation, Stettbachstrasse 6, 8600

Dübendorf, Switzerland

Full list of author information is available at the end of the article
} 


\section{Background}

Children are at a high risk of injury with up to one of every four children sustaining an injury annually $[1,2]$. Fractures are associated with $10 \%$ to $25 \%$ of these injuries [3], where the lifetime fracture risk is up to $40 \%$ for girls and as high as up to $64 \%$ for boys [4-9]. With fractures having a considerable impact on the daily living and activity of affected children, they represent an important topic of public health $[10,11]$.

In 2007, the AO Pediatric Comprehensive Classification of Long Bone Fractures (PCCF) [12] was developed and validated according to a 3-phase concept proposed by Audigé et al. [13]. The initial two validation phases showed that the classification process based on radiographic assessment is reliable and accurate [14,15] and that the PCCF system can be considered clinically relevant by pediatric surgeons. The AO Comprehensive Injury Automatic Classifier (AO COIAC) software [16] was developed for testing in a clinical setting following the 3rd and final validation phase, with the purpose of fully documenting and evaluating pediatric long bone fractures, their causes, classification codes, treatments, occurrence of associated complications, and outcomes.

Different risk factors for sustaining fractures in children have been reported, such as age, sex, season, risk-taking behavior, bone mineral density (BMD), sports, but also violence and race/ethnicity and socioeconomic status [4,11,17-22]. Overweight and obesity seem to have an increasing impact [23-28], possibly due to lower bone mass relative to body size, greater mechanical load by falls or reduced body balance [17,20,29-31], and therefore, became major topics of interest for both treating physicians and public health [32].

As the amount of data is still limited, further epidemiological data are needed to better understand the occurrence of pediatric long bone fractures and for the planning of future prevention strategies. The aim of this retrospective cohort study was to review the demographic data of all recorded pediatric long bone fractures at the University Children's Hospitals in Bern and Lausanne and to evaluate any differences between these data. This is the first time that a large patient cohort was classified according to the AO PCCF using the AO COIAC software to collect epidemiological data on pediatric long bone fractures.

\section{Methods}

The present study was a retrospective cohort study to survey fractures with open physes in children and adolescents younger than 17 years of age in Switzerland. All fractures were sustained between January 2009 and December 2011. Inclusion criteria were documented pediatric long bone fractures in children (in- and outpatient cases) treated at the University Children's Hospitals in Bern
(Inselspital) and Lausanne. Ethical approval from the regional ethic committees (ethical commission canton of Bern, Bern, Switzerland and ethical commission canton of Vaud, Lausanne, Switzerland) was obtained for both clinics. The Children's Hospital in Lausanne is a tertiary care university hospital, serving as a primary care center for the city of Lausanne, which has approximately 160 '000 inhabitants. The Children's Hospital in Bern is also a tertiary care university hospital, serving as a primary care center for the city of Bern, with a population of 170 '000, and the adjacent cities. Being the only children's hospitals in the aforementioned cities, a majority of children up to the age of 16 are treated in these hospitals (approx. 80\%). Twenty-four-hour in- and outpatient primary emergency service is provided to patients for both cities, but also for the entire cantons of Bern and Vaud and the adjoining cantons.

All long bone fractures were classified by an experienced pediatric trauma surgeon in each clinic using the $\mathrm{AO}$ PCCF system [15] on the basis of digitalized anteroposterior and lateral view radiographs. Documentation of all classified data was made using the specialized $\mathrm{AO}$ COIAC software [33], which facilitates the diagnosis and coding of fractures (Figure 1). In addition to fracture classification, available epidemiological data including age, sex, body mass index (BMI), date and time of injury, cause of injury and data concerning treatment (extracted from digitalized or paper patient charts) were recorded.

Patients were classified into four age groups including: 1) infants ( $<2$ years); 2 ) preschool children ( 2 to $<6$ years); 3) school children ( 6 to $<11$ years); and 4 ) adolescents (11 to $<17$ years). The type of accident was divided into seven major categories: 1) home accidents (including all those occurring within the house and yard except on playing devices, e.g. trampoline); 2) school accidents (including accidents occurring at school or kindergarten); 3) playground accidents (including all accidents occurring on public and private playgrounds as well as all accidents with outdoor playing devices); 4) leisure activities; 5) traffic accidents (including all accidents associated with any kind of transportation); 6) falls and 7) others (including long bone fractures due to non-accidental injuries or any undefined accident types). Furthermore, differentiations were made between boys and girls, upper and lower limbs and the time at which fractures were sustained.

For most of the patients undergoing a conventional radiograph at the Children's Hospital in Bern, height and weight measurements were documented prior to the examination to adapt the individual's radiation exposure. Therefore, retrospective BMI calculations were possible for these patients. Using this baseline characteristic, the BMI distribution of this subpopulation was compared to the World Health Organization (WHO) BMI-for-age percentiles for boys and girls [34] to further explore BMI as a 


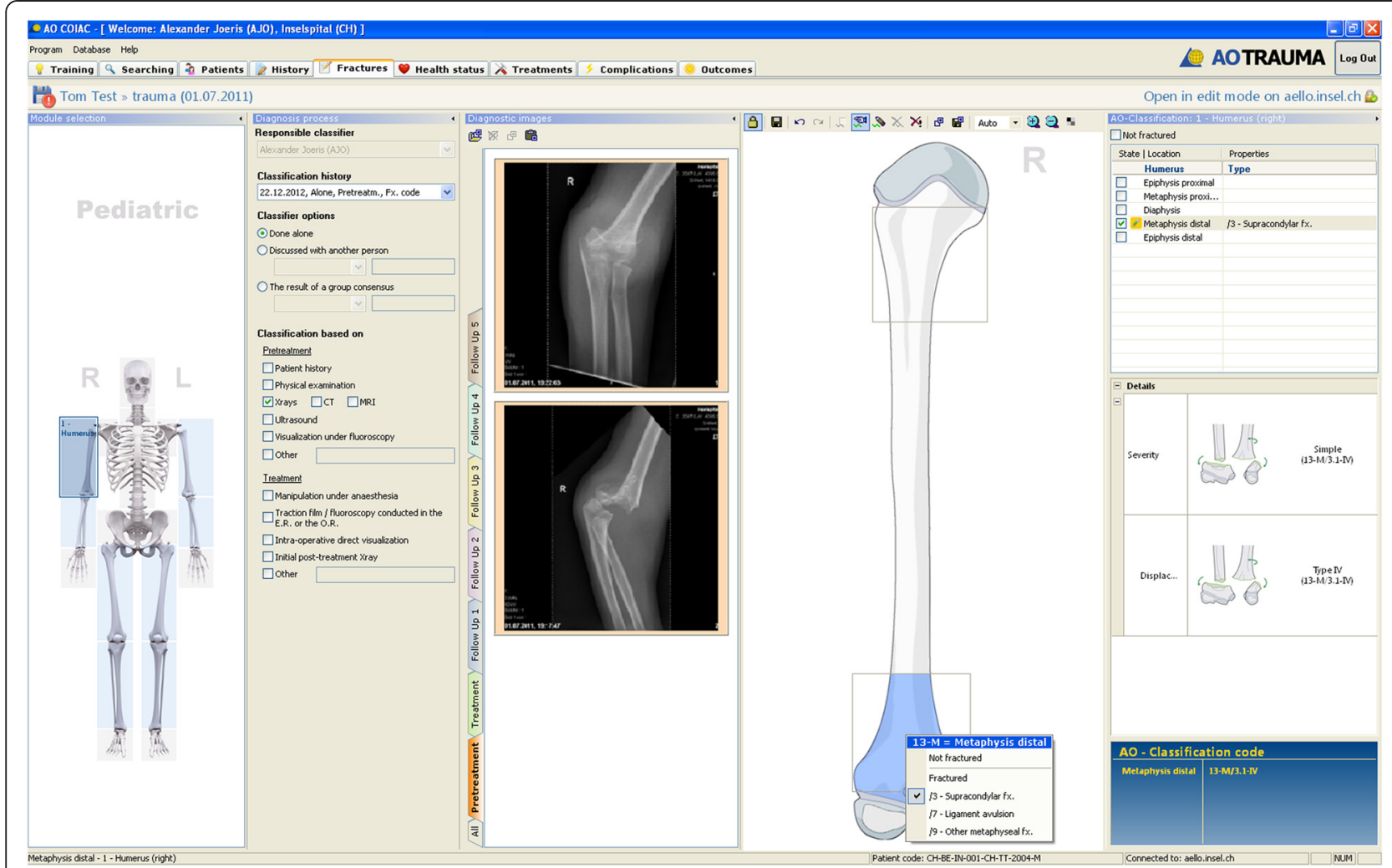

Figure 1 Screenshot of the AO COIAC interface. The AO COIAC interface aids through the classification process. To classify a fracture, one can either click on the depicted standard bone or one can draw fracture lines in the bone. Drop down menus and classification options optimize the classification afterwards.

potential risk factor for pediatric fractures. Severe thinness is defined as a BMI at or above the 3rd percentile and below the 15th percentile for children of the same age and sex; thinness as a BMI at or above the 15th percentile and below the 50th percentile; normal weight children present with a BMI at or above the 50th percentile and below the 85th percentile; overweight children with a BMI at or above the 85th and below the 97th percentile and obesity is defined as a BMI at or above the 97th percentile. For the BMI-for-age percentiles in children $<2$ years, the WHO recommends adding or subtracting $0.7 \mathrm{~cm}$ from the height before calculating the BMI, depending on whether the child's height was measured in a standing or lying position, respectively. As it was not known whether the height of children aged $<2$ years was measured while standing or lying, BMI calculations were not applicable for this group, and infants were excluded from BMI calculations. In order to compare the proportion of overweight and obese children in our study population to the overall Swiss population in patients aged between 6 and 12 years (as grouped by Swiss surveys before), we exclusively amended our patient group and additionally performed this analysis in children aged 6 to12 years.
All data collected with AO COIAC were transferred into Intercooled Stata version 12 (StataCorp LP, College Station, TX, USA). Study parameters were analyzed and tabulated using standard descriptive statistics. The one-sample test of proportions was used to compare the proportions of overweight and obese children in boys and girls aged between 6 and 12 years in this study with those in boys $(18.7 \%)$ and girls $(17.0 \%)$ in the same age category in Switzerland (i.e. with a BMI above the $85^{\text {th }}$ percentile), respectively. The chi-square test was used to assess the relationship between two categorical variables (e.g. BMI classes and age classes).

\section{Results}

\section{Study collective}

A total of 2716 patients (Bern: $\mathrm{n}=1066$; Lausanne: $\mathrm{n}=1650 ; 60 \%$ boys) who experienced 2807 accidents were included into the study. While a single accident was documented for 2630 patients, multiple accidents were recorded for 86 patients. Fifty-one patients sustained more than one fracture during the same accident, either in the same bone $(n=20)$ or different bones $(n=31)$ (Figure 2). Of 2840 fractures, $33(1 \%)$ were classified as open fractures according to 


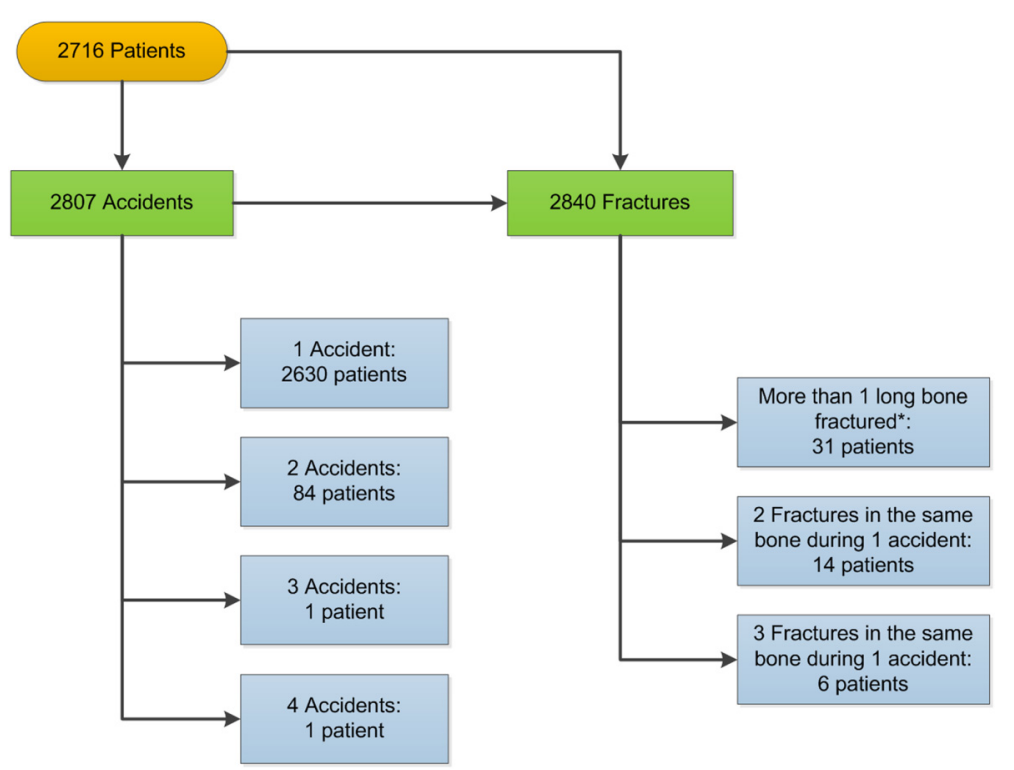

Figure 2 Overview of patients, accidents and fractures. Relation between patients, accidents occurred and sustained long bone fractures. * Fractures of the radius and ulna as well as tibia and fibula were considered as one fractured long bone.

Gustilo et al. [35,36] and included 23 Grade I fractures, nine Grade II fractures and one Grade III fracture.

According to the predefined age groups, 176 infants (6\%), 699 preschool children (26\%), 1074 school children $(40 \%)$ and 767 adolescents $(28 \%)$ sustained a fracture. The overall mean age was 8.2 years $(\mathrm{SD} \pm 4.0$; range $0-17.6$ years).

More boys sustained a fracture (60\%; odds: $1.5: 1)$. In infants, the sex distribution was equal ( $50 \%$ boys, $50 \%$ girls), but changed towards a distinct predominance of boys in the adolescent subgroup (71\%; odds: $2.4: 1 ; \mathrm{p}<0.001$ ) (Figure 3). Among preschool and school children the proportion of boys was still $56 \%$ in each group.

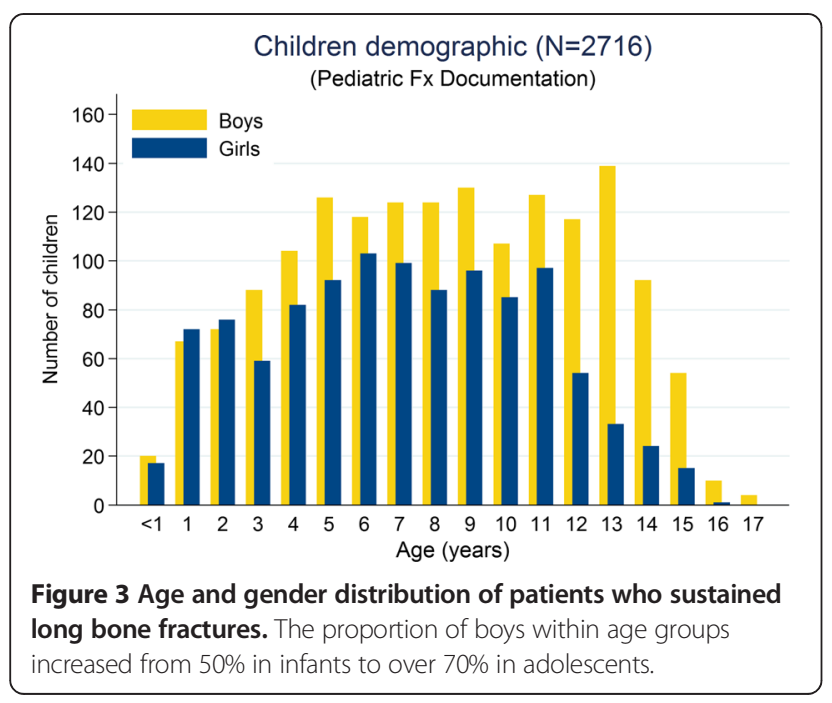

Common concomitant diseases including osteogenesis imperfecta, dysraphism, and neuromuscular or metabolic diseases were reported for 73 patients (2.7\%).

\section{Body mass index}

Body mass index data could be analyzed for 791 out of 875 patients from the Children's Hospital in Bern for whom weight and height measurements were documented. The mean BMI for patients with height and weight measurements was $17.3 \mathrm{~kg} / \mathrm{m}^{2}$ ( $\mathrm{SD} \pm 3.1$; range 9.8-34.0). According to the WHO BMI-for-age percentile curves, 210 children (27\%) were categorized as either overweight or obese in this study. Whereas the proportion of children with normal weight remained stable $(61 / 62 \%)$, the proportion of thin children decreased with age ( $9 \%$ to $3 \%)$ while the proportion of overweight children increased with age ( $12 \%$ to $19 \% ; \mathrm{p}=0.018)$. Accordingly, the highest proportion of overweight patients were adolescents (19\%; $\mathrm{n}=46)$ followed by school children $(14 \% ; n=45)$ and preschool children $(12 \% ; n=30)$. Obesity was most frequently seen in school children $(13 \% ; n=40)$ followed by adolescents $(10 \% ; n=24)$ and preschool children $(10 \% ; n=25)$ (Table 1). Compared to the overall Swiss 6 to 12 years old (surveyed in 2009), we found a significant higher proportion of overweight and obese boys (33\% vs. $18.7 \%$; $\mathrm{p}<0.0001$ ) and a non-significant higher proportion of overweight and obese girls ( $20 \%$ vs. $17 \% ; \mathrm{p}=0.12)$ in this age group. All age groups combined, the proportion of overweight and obese patients was similar whether patients had a fracture in the upper limb $(26 \%)$ or the lower $\operatorname{limb}(30 \% ; \mathrm{p}=0.39)$. 
Table 1 Distribution of the pediatric long bone fracture population based on gender and BMI classes in patients from the Children's Hospital in Bern

\begin{tabular}{|c|c|c|c|c|c|c|c|c|}
\hline & \multicolumn{2}{|l|}{ Gender } & \multicolumn{6}{|l|}{ WHO BMI classes } \\
\hline & Girls & Boys & Severe Thinness $^{1}$ & Thinness $^{2}$ & Normal $^{3}$ & Overweight $^{4}$ & Obesity $^{5}$ & Total $^{6}$ \\
\hline Age group & $\mathrm{N}(\%)^{7}$ & $\mathrm{~N}(\%)$ & $\mathrm{N}(\%)$ & $\mathrm{N}(\%)$ & $N(\%)$ & $\mathrm{N}(\%)$ & $\mathrm{N}(\%)$ & $\mathrm{N}(\%)$ \\
\hline Infants ( $<2$ years) & $40(48)$ & $44(52)$ & n.a. & n.a. & n.a. & n.a. & n.a. & n.a. \\
\hline Preschool children ( 2 to $<6$ years) & $139(45)$ & $173(55)$ & $21(9)$ & $16(7)$ & $149(62)$ & $30(12)$ & $25(10)$ & $241(100)$ \\
\hline School children ( 6 to $<11$ years) & $165(44)$ & $214(56)$ & $9(3)$ & $27(9)$ & $192(61)$ & $45(14)$ & $40(13)$ & $313(100)$ \\
\hline Adolescents (11 to 17 years) & $95(33)$ & $196(67)$ & $7(3)$ & $15(6)$ & $145(61)$ & 46 (19) & $24(10)$ & 237 (100) \\
\hline Total & $439(41)$ & $627(59)$ & $37(5)$ & $58(7)$ & $486(62)$ & $121(15)$ & $89(11)$ & $791(100)$ \\
\hline
\end{tabular}

$\mathrm{WHO}=$ World Health Organization; $\mathrm{BMI}=$ Body Mass Index; n.a. = not available.

${ }^{1} \mathrm{BMI}$ at or above the 3rd percentile and below the 15 th percentile for children of the same sex and age.

${ }^{2} \mathrm{BMI}$ at or above the 15th percentile and below the 50th percentile for children of the same sex and age.

${ }^{3} \mathrm{BMI}$ at or above the 50th percentile and below the 85 th percentile for children of the same sex and age.

${ }^{4} \mathrm{BMI}$ at or above the 85 th percentile and below the 97 th percentile for children of the same sex and age.

${ }^{5} \mathrm{BMl}$ at or above the 97 th percentile for children of the same sex and age.

${ }^{6}$ Total of patients for whom BMI data could be calculated. For 275 children either height measurements (children under 2 years of age) were incomplete or both height and weight measurements were missing.

${ }^{7}$ Percentage of children within each of the four age groups.

\section{Type of accident}

For 107 (4\%) fractures, the injury mechanism was not evaluated due to insufficient documentation in the patient charts. The leading cause for long bone fractures was falls (27\%) (Table 2), with a majority of fractures resulting from falling from a height less than 1 meter (57\%), followed by falling from an unknown height (22\%) and falling from a height greater than 1 meter (21\%).

Leisure activities were the second most frequent cause of fractures $(25 \% ; n=695)$, with those activities pursued in organized sports clubs, representing $5 \%(n=153)$ of all accidents. Out of the 153 accidents sustained in sports clubs, $90 \%(\mathrm{n}=138)$ involved boys and almost three-quarters $(73 \% ; \mathrm{n}=112)$ occurred while playing soccer. Overall, playing soccer was the main reason for sustaining a long bone fracture during leisure activities $(26 \% ; n=182)$ (Table 3$)$.
Accidents occurring at home were the third most frequent cause of fractures (14\%), followed by playground accidents (11\%), traffic accidents (11\%) and school accidents (8\%). Playground accidents occurred mainly whilst playing on swings (32\%), slides (29\%) and trampolines (22\%) (Table 4). Bicycle (45\%) and non-motorized scooter accidents (35\%) represented the main modes for sustaining traffic accident-related fractures; on the other hand, $11 \%$ of the pediatric population sustained a fracture as a pedestrian with only $3 \%$ injured as car passengers (Table 5). Nearly two thirds of all fractures sustained at school occurred whilst undertaking school sport activities (64\%). Playground accidents and accidents at home occurred equally for boys and girls, while the remaining accident types (school, leisure activities, fall, traffic, at home and others) reflected the overall sex distribution of $60 \%$ boys and $40 \%$ girls (Table 2 ).

Table 2 Distribution of accident types within sex and age groups

\begin{tabular}{|c|c|c|c|c|c|c|c|c|}
\hline & Girls & Boys & Age (yrs) & $\begin{array}{l}\text { Infants } \\
(<2 \text { yrs })\end{array}$ & $\begin{array}{l}\text { Pre-school children } \\
\text { ( } 2 \text { to }<6 \text { yrs) }\end{array}$ & $\begin{array}{l}\text { School children } \\
\text { ( } 6 \text { to }<11 \text { yrs) }\end{array}$ & $\begin{array}{l}\text { Adolescents } \\
\text { (11 to } 17 \text { yrs) }\end{array}$ & Total \\
\hline Type of accident & $N(\%)$ & $N(\%)$ & Mean & $\mathrm{N}(\%)$ & $\mathrm{N}(\%)$ & $N(\%)$ & $N(\%)$ & $\mathrm{N}$ \\
\hline School/kindergarten & $84(8)$ & $148(9)$ & 9.9 & $4(2)$ & $25(3)$ & $103(9)$ & $100(13)$ & $232(8)$ \\
\hline Playground & $152(14)$ & $168(10)$ & 6.6 & $20(11)$ & $128(18)$ & $136(12)$ & $36(5)$ & $320(11)$ \\
\hline Leisure activities $^{1}$ & $227(20)$ & $468(28)$ & 10.3 & $4(2)$ & $79(11)$ & $291(26)$ & $321(40)$ & $695(25)$ \\
\hline Fall & $312(28)$ & $449(27)$ & 7.7 & $38(22)$ & $220(30)$ & $353(32)$ & $150(19)$ & $761(27)$ \\
\hline Traffic & $121(11)$ & $191(11)$ & 9.3 & $4(2)$ & $71(10)$ & $118(11)$ & $119(15)$ & $312(11)$ \\
\hline At home & $174(16)$ & $206(12)$ & 4.9 & $92(52)$ & $179(25)$ & $71(6)$ & $38(5)$ & $380(14)$ \\
\hline Other ${ }^{2}$ & $45(4)$ & $62(4)$ & 8.0 & $14(8)$ & $20(3)$ & $41(4)$ & $32(4)$ & $107(4)$ \\
\hline Total & 1115 (100) & 1692 (100) & 8.2 & $176(100)$ & $722(100)$ & $1113(100)$ & 796 (100) & 2807 (100) \\
\hline
\end{tabular}

${ }^{1}$ Including a total of 153 sports club activities.

${ }^{2}$ Not evaluated due to insufficient documentation in the patient charts. 
Table 3 Specific activities associated with the occurrence of pediatric fractures during leisure activities

\begin{tabular}{|c|c|c|c|c|c|}
\hline \multirow[t]{2}{*}{$\begin{array}{l}\text { Type of leisure } \\
\text { activity accident }\end{array}$} & \multirow{2}{*}{$\begin{array}{l}\text { Infants }(<2 \text { yrs }) \\
\mathrm{N}\end{array}$} & \multirow{2}{*}{$\begin{array}{l}\text { Pre-school children } \\
(2 \text { to < } 6 \text { yrs) } \\
N(\%)\end{array}$} & \multirow{2}{*}{$\begin{array}{l}\text { School children } \\
\text { (6 to < } 11 \text { yrs) } \\
N(\%)\end{array}$} & \multirow{2}{*}{$\begin{array}{l}\text { Adolescents } \\
\text { (11 to } 17 \text { yrs) } \\
\mathrm{N}(\%)\end{array}$} & \multirow{2}{*}{$\begin{array}{l}\text { Total } \\
\text { N (\%) }\end{array}$} \\
\hline & & & & & \\
\hline Soccer $^{1}$ & - & $5(6)$ & $72(25)$ & $105(33)$ & $182(26)$ \\
\hline Skiing & 2 & $35(44)$ & $40(14)$ & $38(12)$ & $115(17)$ \\
\hline Rollerblade & - & $3(4)$ & $35(12)$ & $23(7)$ & $61(9)$ \\
\hline Ice skating/ice hockey & - & $7(9)$ & $25(9)$ & $27(8)$ & $59(8)$ \\
\hline Unclassified leisure activities & 1 & $7(9)$ & $23(8)$ & $19(6)$ & $50(7)$ \\
\hline Horse & - & $5(6)$ & $22(8)$ & $11(3)$ & $38(5)$ \\
\hline Ball against hand & - & - & $21(7)$ & $13(4)$ & $34(5)$ \\
\hline Snowboard & - & - & $5(2)$ & $27(8)$ & $32(5)$ \\
\hline Skateboard & - & 2 & $10(3)$ & $14(4)$ & $26(4)$ \\
\hline Sledding & - & $5(6)$ & $12(4)$ & $9(3)$ & $26(4)$ \\
\hline Running & 1 & $6(8)$ & $7(2)$ & $5(2)$ & $19(3)$ \\
\hline Gymnastic & - & 3 & $4(1)$ & $7(2)$ & $14(2)$ \\
\hline Judo & - & - & $5(2)$ & $7(2)$ & $12(2)$ \\
\hline Basketball & - & - & 3 & 3 & $6(1)$ \\
\hline Motocross & - & - & 2 & 3 & $5(1)$ \\
\hline Rugby & - & - & 1 & 4 & $5(1)$ \\
\hline Mountain bike & - & - & - & 2 & 2 \\
\hline Uni hockey & - & - & - & 2 & 2 \\
\hline Badminton & - & - & 1 & - & 1 \\
\hline Handball & - & - & 1 & - & 1 \\
\hline Rings & - & - & - & 1 & 1 \\
\hline Schwingen ${ }^{2}$ & - & - & 1 & - & 1 \\
\hline Tennis & - & - & 1 & - & 1 \\
\hline Unicycle & - & - & - & 1 & 1 \\
\hline Table tennis & - & 1 & - & - & 1 \\
\hline Total & 4 & 79 (100) & $291(100)$ & $323(100)$ & 695 (100) \\
\hline
\end{tabular}

1 Soccer accidents including 111 soccer related fractures during club-sport-activities

2 Style of folk wrestling native to Switzerland.

Table 4 Specific activities associated with the occurrence of pediatric fractures on playgrounds

\begin{tabular}{|c|c|c|c|c|c|}
\hline \multirow[t]{2}{*}{$\begin{array}{l}\text { Type of playground } \\
\text { accident }\end{array}$} & $\begin{array}{l}\text { Infants } \\
(<2 \text { yrs })\end{array}$ & $\begin{array}{l}\text { Pre-school children } \\
\text { ( } 2 \text { to }<6 \text { yrs) }\end{array}$ & $\begin{array}{l}\text { School children } \\
\text { ( } 6 \text { to }<11 \text { yrs) }\end{array}$ & $\begin{array}{l}\text { Adolescents } \\
\text { (11 to } 17 \text { yrs) }\end{array}$ & Total \\
\hline & N (\%) & N (\%) & $\mathrm{N}(\%)$ & $\mathrm{N}(\%)$ & N (\%) \\
\hline Swing & $5(25)$ & $34(27)$ & $52(38)$ & $11(31)$ & $102(32)$ \\
\hline Slide & $13(65)$ & $52(41)$ & $24(18)$ & $3(8)$ & $92(29)$ \\
\hline Trampoline & - & $25(20)$ & $35(26)$ & $9(25)$ & $69(22)$ \\
\hline Climbing & - & $11(9)$ & $16(12)$ & $5(14)$ & $32(10)$ \\
\hline Turntable & 1 & 2 & $7(5)$ & 2 & $12(4)$ \\
\hline Carousel & 1 & 1 & 2 & $5(14)$ & $9(3)$ \\
\hline Seesaw & - & 1 & - & 1 & 2 \\
\hline Playing device & - & 1 & - & - & 1 \\
\hline Wall bars & - & 1 & - & - & 1 \\
\hline Total & $20(100)$ & $128(100)$ & $136(100)$ & $36(100)$ & $320(100$ \\
\hline
\end{tabular}


Table 5 Specific activities associated with the occurrence of pediatric fractures in traffic

\begin{tabular}{|c|c|c|c|c|c|}
\hline \multirow[t]{2}{*}{$\begin{array}{l}\text { Type of traffic } \\
\text { accident }\end{array}$} & Infants $(<2$ yrs $)$ & $\begin{array}{l}\text { Pre-school children } \\
\text { ( } 2 \text { to }<6 \text { yrs) }\end{array}$ & $\begin{array}{l}\text { School children } \\
\text { ( } 6 \text { to }<11 \text { yrs) }\end{array}$ & $\begin{array}{l}\text { Adolescents } \\
\text { (11 to } 17 \mathrm{yrs} \text { ) }\end{array}$ & Total \\
\hline & $\mathrm{N}(\%)$ & $\mathrm{N}(\%)$ & $\mathrm{N}(\%)$ & $\mathrm{N}(\%)$ & $\mathrm{N}(\%)$ \\
\hline Bicycle & 1 & $40(56)$ & $41(35)$ & $58(49)$ & $140(45)$ \\
\hline Non-motorized scooter & 1 & $15(21)$ & $56(47)$ & $38(32)$ & $110(35)$ \\
\hline Pedestrian & 1 & $7(10)$ & $19(16)$ & $10(8)$ & $37(12)$ \\
\hline Car passenger & - & $7(10)$ & 2 & 1 & $10(3)$ \\
\hline Motor scooter driver & 1 & - & - & $9(8)$ & $10(3)$ \\
\hline Motor scooter passenger & - & 1 & - & 2 & 3 \\
\hline Other & - & 1 & - & 1 & 2 \\
\hline Total & 4 & $71(100)$ & $118(100)$ & $119(100)$ & $312(100)$ \\
\hline
\end{tabular}

Fractures sustained from school, leisure activities and traffic accidents were associated with higher proportions of patients with increasing age, whereas home accidentrelated long bone fractures, being the leading cause of fractures in infants (52\%) and preschool children (25\%), were significantly less frequent in school children and adolescents ( $6 \%$ and $5 \%$, respectively) ( $\mathrm{p}<0.001)$. Fractures sustained from a fall increased in preschool and school children, but became less frequent in adolescents (Figure 4).

A high proportion of fractures caused by undertaking leisure-activities (33\%) was observed during the winter months (i.e. December to March); 232 fractures were sustained from skiing, snowboarding, ice skating or sledding, with $50 \%$ caused by skiing accidents. For all skiing accident-related fractures, there was an approximately equal distribution among preschool children $(n=35)$, school children $(n=40)$ and adolescents $(n=38)$. Fractures caused by playground accidents occurred mainly between March and October, while no seasonal distribution was observed for school accidents.

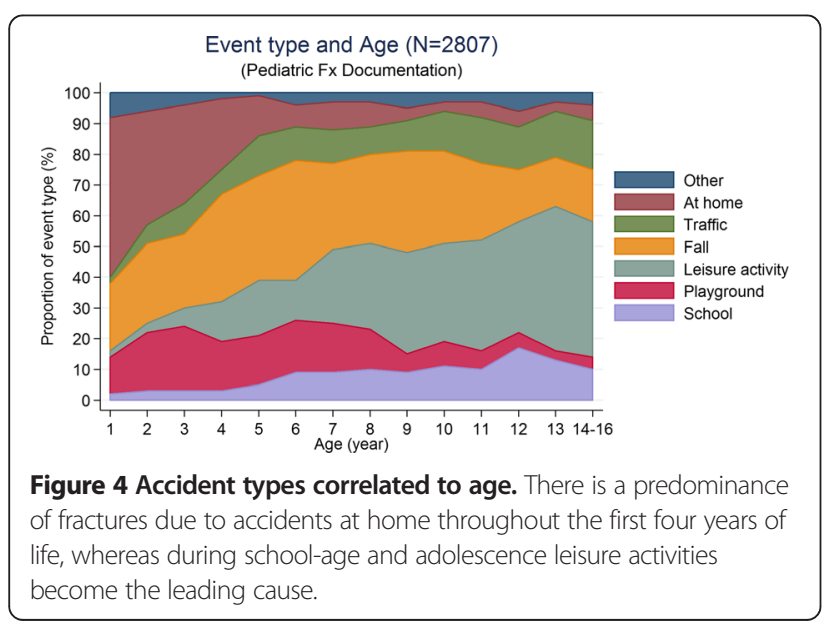

\section{Fracture distribution}

The most commonly reported long bone fractures involved those of the forearm (59\%; $n=1690)$ followed by fractures of the upper $\operatorname{arm}(21 \% ; n=602)$, the lower leg $(15 \% ; n=$ $413)$ and the femur $(5 \% ; n=135)$ (Table 6). Forearm fractures were significantly more frequent in school children (65\%) and adolescents (63\%) compared to infants and preschool children (42\% and 50\%, respectively). Femoral fractures were more frequently observed in the infant group (13\%) compared to around 3\% to $6 \%$ for the other age groups. Femoral fractures were mostly reported for boys (72\%), whereas all other long bone fracture types were distributed equally between boys and girls $(\mathrm{p}=0.011)$. Fractures of the radius and ulna represented the largest proportion (around 60\%) within each accident category, except for home accidents (53\%). Playground and leisure activity categories included several activities (e.g. climbing on playgrounds, soccer, snowboarding, ice skating or running) where forearm fractures accounted for more than $70 \%$ of all fractures sustained. Furthermore, within the traffic category, $70 \%$ of all fractures involving non-motorized scooters were fractures of the radius and ulna.

Of all lower leg fractures occurring during leisure activities, 51\% resulted from skiing accidents. The distribution of fractured bones significantly differed among the types of accidents $(\mathrm{p}<0.001)$.

Only 3 long bone fractures were documented as related to non-accidental injuries.

\section{Discussion}

In the presented study we were able to describe distinct age and sex related differences in the fractured bone distribution and different accident types. Furthermore, compared with the overall Swiss population of similar age, we identified a higher percentage of overweight and obese children in our study population. This observation suggests that overweight and obese children are at increased risk of sustaining a fracture. 
Table 6 Long bone fracture distribution within age groups and sex

\begin{tabular}{|c|c|c|c|c|c|c|c|c|c|}
\hline & Infants ( & $<2$ yrs) & Pre-scho & ren $(2$ to $<6 \mathrm{yrs})$ & School ch & ( 6 to $<11$ yrs) & Adolesce & (11 to $17 \mathrm{yrs}$ ) & Total \\
\hline & Girls & Boys & $\overline{\text { Girls }}$ & Boys & $\overline{\text { Girls }}$ & Boys & $\overline{\text { Girls }}$ & Boys & \\
\hline Bone & N (\%) & N (\%) & N (\%) & $N(\%)$ & N (\%) & N (\%) & N (\%) & N (\%) & $N(\%)$ \\
\hline Humerus & $14(16)$ & $11(13)$ & $97(31)$ & $130(32)$ & $112(23)$ & $131(21)$ & $35(15)$ & $72(13)$ & $602(21)$ \\
\hline Radius/ulna & $39(43)$ & $35(40)$ & $172(55)$ & $192(46)$ & $310(64)$ & $425(67)$ & $142(60)$ & $375(65)$ & $1690(59)$ \\
\hline Femur & $7(8)$ & $16(18)$ & $10(3)$ & $30(7)$ & $17(3)$ & $18(3)$ & $4(2)$ & $33(6)$ & $135(5)$ \\
\hline Tibia/fibula & $30(33)$ & $25(29)$ & $36(11)$ & $60(15)$ & $49(10)$ & $63(10)$ & $54(23)$ & $96(17)$ & $413(15)$ \\
\hline Total & $90(100)$ & $87(100)$ & $315(100)$ & $412(100)$ & $488(100)$ & $637(100)$ & $235(100)$ & $576(100)$ & $2840(100)$ \\
\hline
\end{tabular}

While the overall predominance of fractures sustained by boys over girls with odds of 1.5:1 was consistent with current knowledge [11,20], these odds varied according to our predefined age groups. Biological and behavioral differences related to sex and age are thought to particularly explain the male predominance in the adolescent patient group. BMD decreases towards the age of pubertal peak height velocity with girls experiencing this peak earlier than boys [37]. This biological effect might contribute to the male predominance in adolescents in this study and reflects the finding of Faulkner et al. that the decrease in BMD in adolescents did coincide with an increase of accidents while accidents decreased as BMD rebounded after peak height velocity [37]. Furthermore, a behavioral change in the types of general activities undertaken as well as the level of risk taking can be observed with increasing age.

In accordance with published data, boys were more likely to sustain femoral fractures $[38,39]$. However, we did not observe a bimodal distribution of these fracture types with peaks around the ages of 2 to 5 and 14 to 17 years as reported by Hinton et al. [40]. One explanation for the lack of the second peak could be the small amount of motor vehicle accident-related long bone fractures reported in this study compared to other studies [39-41]. High-energy injuries, especially those sustained during motor vehicle accidents, are thought to be the main reason for femoral fractures in adolescents [39,41].

Petersen et al. reported a doubling in the prevalence of overweight and obese children and adolescents from 1986 to 2001 , reaching $23.1 \%$ (18.3\% overweight and $4.8 \%$ obese children) at or above the $85^{\text {th }}$ BMI-for-age related percentile [42]. Our study population showed a slightly higher proportion that significantly increased with increasing age; this observation may reflect the known global trend of mounting numbers of overweight and obese children and adolescents as predicted by the WHO [32], but more likely reflects the relationship between overweight status and fracture risk.

National Swiss surveys found a decrease in the number of overweight and obese children between 2002 and 2007 following a stabilization in the prevalence of childhood obesity in 2009; the prevalence of overweight and obesity in children from 6 to 12 years was $19.9 \%$ for boys and $18.9 \%$ for girls in 2002 compared to $18.7 \%$ for boys and $17.0 \%$ for girls in 2009 [43,44]. Compared to the overall Swiss population, the proportions of overweight and obese girls and boys in the same age group were higher in this study, with a significantly higher proportion of overweight boys $(33 \%$; $\mathrm{p}<0.0001)$ and a clear tendency but not significantly higher proportion in girls $(20 \% ; \mathrm{p}=0.12)$. These findings may additionally point towards an increased risk for overweight and obese children for sustaining a fracture.

Kessler et al. [45] reported a statistically significantly higher proportion of lower limb fractures in overweight and obese children. Although we made a similar observation, this relation was not significant in our study.

Though categorized differently, our data confirmed recently published data reporting falls being the leading cause for fractures in children and adolescents $(27 \%$ in this study) with most of the fractures resulting from a fall from low height (57\% within this group) [22].

Children older than 5 years sustain more sport-related injuries as they start to pursue more organized sports activities (i.e. in sports clubs) around this age [20]. There was a shift from home- and playground-related fractures occurring in infants and preschool children towards fractures resulting from sports activities undertaken by the older age groups of our study population. Due to the retrospective data collection, we could not reliably determine whether the respective sports activities were organized or not. The manner in which the "accident type" was categorized is not recognized as standard, although attempts were made to match previous reports to facilitate the comparison of results. While this may be imperfect, sports club-related long bone fractures defined in our population were reported more often for school age and adolescent patients and reflect the above mentioned.

During the winter months a seasonal peak (33\%) of winter leisure activity-related fractures was observed at both Children's Hospitals, Bern and Lausanne.

Consistent with previous reports [46,47], forearm fractures were mainly associated with snowboard accidents, whereas lower leg fractures were mostly sustained while 
skiing. Moreover, $49 \%$ of all lower leg fractures in the 'leisure activities' category were sustained while skiing, and skiing was the main reason for lower leg fractures. The risk of sustaining a fracture during snowboarding has been reported to be twice the risk of sustaining a fracture during skiing $[17,48]$. In our study population, there were 3.5 times more fractures following skiing than following snowboarding; however, this might be explained by the 4.8 times higher proportion of the Swiss population practicing skiing compared to snowboarding [49].

The rising popularity of trampolines in yards and playgrounds has been followed by an increase in trampolinerelated injuries impacting the physical health of children and adolescents [50]. Our study supported this assumption, as together with accidents on slides and swings, trampoline accidents represented one of the three leading causes for playground activity related fractures.

The increased popularity of non-motorized scooters since the beginning of this century [51], especially for school age children and adolescents, was reflected in our study. Besides cycling, non-motorized scooters were the second most frequently reported cause for long bone fractures sustained during traffic accidents.

Finally, we have to acknowledge that our rate of nonaccidental injuries is rather low with only three patients. Most likely, this is due to underreporting and our study focusing on long-bone fractures, but not on nonaccidental injuries in general.

This study has its limitations, in particular, its retrospective study design. Data quality was dependent on the completeness of the patient charts, specifically regarding the accident type. The categorization of pediatric accident data is often prone to error or misclassification because younger children, in particular, may have difficulties in explaining the correct course of events or the accident occurred unobserved. The fact that approximately $80 \%$ of all pediatric long bone fractures are treated in the Children's hospitals in Bern and Lausanne could lead to potential publication biaz assuming that the remaining $20 \%$ of long bone fractures could present differently. As the two hospitals do not cover $100 \%$ of patients of the respective regions, epidemiological data such as incidences could not be provided. Nonetheless, the large cohort is a strength of this study.

\section{Conclusion}

In conclusion, our retrospective cohort study provided valuable epidemiological data about pediatric long bone fractures in a large Swiss cohort of children and adolescents and may contribute to the development of appropriate prevention strategies in the future. Comprehensive epidemiological data could also serve as a future teaching aid to orthopedic and trauma surgeons in training.
The AO PCCF system was successfully used to classify all encountered fractures; the detailed fracture patterns however were beyond the scope of this paper. The AO COIAC software proved to be practical and useful in the clinical context, providing the basis for a standardized, multicenter documentation of pediatric long bone fractures. We encourage any hospital treating pediatric fractures to adopt the AO PCCF system and use the freely available AO COIAC software [16].

\section{Competing interests}

The authors declare that they have no competing interests.

\section{Authors' contributions}

AJ collected all clinical data from the Children's Hospital in Bern and was involved in overall data analysis and interpretation. As the first author of the manuscript he provided the first draft and gave his input for all further drafts. NL collected all clinical data from the Children's Hospital in Lausanne, contributed to data analysis and reviewed the manuscript. BW was the Scientific Medical Affairs Manager and Head of AOCID Fellows during the time AJ completed his AOCID Clinical Research Fellowship. She mentored him and participated in the preparation and review of this manuscript. TS was one of the main contributors and the initiator of the development of the PCCF and AO COIAC. He was involved in data analysis and interpretation and reviewed the manuscript. LA was the overall project methodologist and coordinator included in the development and introduction of AO COIAC in the participating clinics. He was the mentor of AJ during his fellowship at AO Clinical Investigation and Documentation (AOCID) and supervised this project. He performed the majority of data analyses, and participated in the preparation of this manuscript. All authors read and approved the final manuscript.

\section{Authors' information}

Joeris A. is a pediatric surgeon, who worked for 10 years at the Children's Hospital in Bern, Switzerland, mainly in pediatric traumatology and orthopedics. He was involved in the second AO PCCF validation phase. He completed a 6-month fellowship at AOCID between July and December 2012. Since April 2013 he holds the position of the Medical Scientific Affairs Manager at AOCID and is globally involved in a broad spectrum of clinical trials in traumatology and orthopedics. Lutz N. is a general and pediatric trauma surgeon with more than 15 years experience in pediatric traumatology at a tertiary care center. He is especially interested in pediatric fractures and obesity. Currently, he holds the position head of pediatric surgical emergencies in the University Hospital in Lausanne in Switzerland and works as a partner for the pediatric orthopedic and traumatology units at the same hospital. Wicki B. is a physician with a postgraduate degree in Pharmaceutical Medicine and over 20 years of in-depth clinical development experience with expertise in multiple therapeutic areas. She currently holds the position of a Principal Medical Writer II at Celgene International in Boudry, Switzerland. Slongo T. is a pediatric surgeon who was the head of the pediatric traumatology and orthopedics division at the Children's Hospital in Bern, Switzerland for more than 30 years. Additionally he was the deputy head of the department for pediatric surgery at the same hospital for many years. He was a member of the AO Classification Advisory Group and therefore involved in the development of the AO PCCF and its validation and the development of AO COIAC. Audigé L. is a clinical epidemiologist and has worked since 2000 as methodologist for AOCID in the implementation of clinical studies in the field of traumatology and orthopedics. He was coordinator of the AO Classification Advisory Group and led several Classification Groups, in particular for the development and validation of the AO PCCF. He currently holds the position of Senior Research Fellow at the Schulthess Clinic in Zurich Switzerland.

\section{Acknowledgements}

The authors would like to thank Andrea Sebald for her helpful hands in copy-editing this manuscript (AOCID). The present clinical investigation was performed with the support of the AO Foundation via the AO Trauma Network. 


\section{Author details}

'Department of Pediatric Surgery, Traumatology and Orthopedics, University Hospital (Inselspital) Bern, Freiburgstrasse 15, 3010 Bern, Switzerland. ${ }^{2} \mathrm{AO}$ Clinical Investigation and Documentation, Stettbachstrasse 6, 8600 Dübendorf, Switzerland. ${ }^{3}$ Centre Hospitalier Universitaire Vaudois (CHUV), Rue du Bugnon 46, 1011 Lausanne, Switzerland. ${ }^{4}$ Research and Development Department, Schulthess Clinic, Lengghalde 2, 8008 Zürich, Switzerland.

Received: 16 January 2014 Accepted: 11 December 2014

Published online: 20 December 2014

\section{References}

1. Scheidt PC, Harel Y, Trumble AC, Jones DH, Overpeck MD, Bijur PE: The epidemiology of nonfatal injuries among US children and youth. Am J Public Health 1995, 85(7):932-938.

2. Walsh SS, Jarvis SN, Towner EM, Aynsley-Green A: Annual incidence of unintentional injury among 54,000 children. Inj Prev 1996, 2(1):16-20.

3. Landin LA: Epidemiology of children's fractures. J Pediatr Orthop B 1997, 6(2):79-83.

4. Cooper C, Dennison EM, Leufkens HG, Bishop N, van Staa TP: Epidemiology of childhood fractures in Britain: a study using the general practice research database. J Bone Miner Res 2004, 19(12):1976-1981.

5. Donaldson LJ, Reckless IP, Scholes S, Mindell JS, Shelton NJ: The epidemiology of fractures in England. J Epidemiol Community Health 2008, 62(2):174-180

6. Gallagher SS, Finison K, Guyer B, Goodenough S: The incidence of injuries among 87,000 Massachusetts children and adolescents: results of the 1980-81 Statewide Childhood Injury Prevention Program Surveillance System. Am J Public Health 1984, 74(12):1340-1347.

7. Jones IE, Williams SM, Dow N, Goulding A: How many children remain fracture-free during growth? a longitudinal study of children and adolescents participating in the Dunedin Multidisciplinary Health and Development Study. Osteoporos Int 2002, 13(12):990-995.

8. Landin LA: Fracture patterns in children. Analysis of 8,682 fractures with special reference to incidence, etiology and secular changes in a Swedish urban population 1950-1979. Acta Orthop Scand Suppl 1983, 202:1-109.

9. Rivara FP, Calonge N, Thompson RS: Population-based study of unintentional injury incidence and impact during childhood. Am J Public Health 1989, 79(8):990-994.

10. Kopjar B, Wickizer TM: Fractures among children: incidence and impact on daily activities. Inj Prev 1998, 4(3):194-197.

11. Valerio G, Galle F, Mancusi C, Di Onofrio V, Colapietro M, Guida P, Liguori G: Pattern of fractures across pediatric age groups: analysis of individual and lifestyle factors. BMC Public Health 2010, 10:656.

12. Slongo TF, Audige L, Group AOPC: Fracture and dislocation classification compendium for children: the $\mathrm{AO}$ pediatric comprehensive classification of long bone fractures (PCCF). J Orthop Trauma 2007, 21(10 Suppl):S135-S160.

13. Audige $L$, Bhandari $M$, Hanson $B$, Kellam J: A concept for the validation of fracture classifications. J Orthop Trauma 2005, 19(6):401-406.

14. Slongo T, Audige L, Clavert JM, Lutz N, Frick S, Hunter J: The AO comprehensive classification of pediatric long-bone fractures: a web-based multicenter agreement study. J Pediatr Orthop 2007, 27(2):171-180.

15. Slongo T, Audige L, Schlickewei W, Clavert JM, Hunter J, International Association for Pediatric T: Development and validation of the AO pediatric comprehensive classification of long bone fractures by the Pediatric Expert Group of the AO Foundation in collaboration with AO Clinical Investigation and Documentation and the International Association for Pediatric Traumatology. J Pediatr Orthop 2006, 26(1):43-49.

16. AO Comprehensive Injury Automatic Classifier (AOCOIAC). [https://www. aofoundation.org/Structure/resource/AO-OTA-Fracture-DislocationClassification/comprehensive-injury-automatic-classifier/Pages/ Comprehensive-Injury-Automatic-Classifier.aspx]

17. Mathison DJ, Agrawal D: An update on the epidemiology of pediatric fractures. Pediatr Emerg Care 2010, 26(8):594-603. quiz 604-596.

18. Brudvik C, Hove LM: Childhood fractures in Bergen, Norway: identifying high-risk groups and activities. J Pediatr Orthop 2003, 23(5):629-634.

19. Caine D, Caine C, Maffulli N: Incidence and distribution of pediatric sport-related injuries. Clin J Sport Med 2006, 16(6):500-513.
20. Hedstrom EM, Svensson O, Bergstrom U, Michno P: Epidemiology of fractures in children and adolescents. Acta Orthop 2010, 81(1):148-153.

21. Rennie L, Court-Brown CM, Mok JY, Beattie TF: The epidemiology of fractures in children. Injury 2007, 38(8):913-922.

22. Schalamon J, Dampf S, Singer G, Ainoedhofer H, Petnehazy T, Hoellwarth $\mathrm{ME}$, Saxena AK: Evaluation of fractures in children and adolescents in a Level I Trauma Center in Austria. J Trauma 2011, 71(2):E19-E25.

23. Brown CV, Neville AL, Salim A, Rhee P, Cologne K, Demetriades D: The impact of obesity on severely injured children and adolescents. J Pediatr Surg 2006, 41(1):88-91. discussion 88-91.

24. Goulding A, Cannan R, Williams SM, Gold EJ, Taylor RW, Lewis-Barned NJ: Bone mineral density in girls with forearm fractures. J Bone Miner Res 1998, 13(1):143-148

25. Lazar-Antman MA, Leet Al: Effects of obesity on pediatric fracture care and management. J Bone Joint Surg Am 2012, 94(9):855-861.

26. Pollack KM, Xie D, Arbogast KB, Durbin DR: Body mass index and injury risk among US children 9-15 years old in motor vehicle crashes. Inj Prev 2008, 14(6):366-371.

27. Rana AR, Michalsky MP, Teich S, Groner Jl, Caniano DA, Schuster DP: Childhood obesity: a risk factor for injuries observed at a level-1 trauma center. J Pediatr Surg 2009, 44(8):1601-1605.

28. Taylor ED, Theim KR, Mirch MC, Ghorbani S, Tanofsky-Kraff M, Adler-Wailes DC, Brady S, Reynolds JC, Calis KA, Yanovski JA: Orthopedic complications of overweight in children and adolescents. Pediatrics 2006, 117(6):2167-2174

29. Dimitri P, Bishop N, Walsh JS, Eastell R: Obesity is a risk factor for fracture in children but is protective against fracture in adults: a paradox. Bone 2012, 50(2):457-466.

30. Dimitri $P$, Wales JK, Bishop N: Fat and bone in children: differential effects of obesity on bone size and mass according to fracture history. J Bone Miner Res 2010, 25(3):527-536.

31. Goulding A, Jones IE, Taylor RW, Piggot JM, Taylor D: Dynamic and static tests of balance and postural sway in boys: effects of previous wrist bone fractures and high adiposity. Gait Posture 2003, 17(2):136-141.

32. de Onis M, Blossner M, Borghi E: Global prevalence and trends of overweight and obesity among preschool children. Am J Clin Nutr 2010 92(5):1257-1264

33. Audigé L, Slongo T, Kellam J, Agel J, Nebel A, Cornelius P, Sauter D: AO COIAC Comprehensive Injury Automatic Classifier User Manual. In., Version 3.0 edn. https://www.aofoundation.org; 2008.

34. The World Health Organization Child Growth Standards. [http://www. who.int/childgrowth/standards/bmi_for_age/en/index.html]

35. Gustilo RB, Anderson JT: Prevention of infection in the treatment of one thousand and twenty-five open fractures of long bones: retrospective and prospective analyses. J Bone Joint Surg Am 1976, 58(4):453-458.

36. Gustilo RB, Mendoza RM, Williams DN: Problems in the management of type III (severe) open fractures: a new classification of type III open fractures. J Trauma 1984, 24(8):742-746.

37. Faulkner RA, Davison KS, Bailey DA, Mirwald RL, Baxter-Jones AD: Size-corrected BMD decreases during peak linear growth: implications for fracture incidence during adolescence. J Bone Miner Res 2006, 21(12):1864-1870

38. Capra L, Levin AV, Howard A, Shouldice M: Characteristics of femur fractures in ambulatory young children. Emerg Med J 2013, 30(9):749-753.

39. Flynn JM, Skaggs DL: Femoral shaft fractures. In: Rockwood and Wilkins' Fractures in children. 7 edition. Edited by Beaty JH, Kasser JR. 530 Walnut Street, Philadelphia, PA 19106 USA: Lippincott Williams \& Wilkins; 2009: 797-841.

40. Hinton RY, Lincoln A, Crockett MM, Sponseller P, Smith G: Fractures of the femoral shaft in children. Incidence, mechanisms, and sociodemographic risk factors. J Bone Joint Surg Am 1999, 81(4):500-509.

41. Hedlund $R$, Lindgren $U$ : The incidence of femoral shaft fractures in children and adolescents. J Pediatr Orthop 1986, 6(1):47-50.

42. Petersen S, Brulin C, Bergstrom E: Increasing prevalence of overweight in young schoolchildren in Umea, Sweden, from 1986 to 2001. Acto Paediatr 2003, 92(7):848-853.

43. Aeberli I, Ammann RS, Knabenhans M, Molinari L, Zimmermann MB: Decrease in the prevalence of paediatric adiposity in Switzerland from 2002 to 2007. Public Health Nutr 2010, 13(6):806-811.

44. Aeberli I, Henschen I, Molinari L, Zimmermann MB: Stabilization of the prevalence of childhood obesity in Switzerland. Swiss Med Wkly 2010, 140:w13046. 
45. Kessler J, Koebnick C, Smith N, Adams A: Childhood obesity is associated with increased risk of most lower extremity fractures. Clin Orthop Relat Res 2013, 471(4):1199-1207.

46. Kim S, Endres NK, Johnson RJ, Ettlinger CF, Shealy JE: Snowboarding injuries: trends over time and comparisons with alpine skiing injuries. Am J Sports Med 2012, 40(4):770-776.

47. Meyers MC, Laurent CM Jr, Higgins RW, Skelly WA: Downhill ski injuries in children and adolescents. Sports Med 2007, 37(6):485-499.

48. Sulheim S, Holme I, Rodven A, Ekeland A, Bahr R: Risk factors for injuries in alpine skiing, telemark skiing and snowboarding-case-control study. Br J Sports Med 2011, 45(16):1303-1309.

49. Brügger O, Bianchi G, Hofer F, Walter M, Michel Fl, Müller C: bfuSicherheitsdossier Nr. 10. In. http://www.bfu.ch/sites/assets/Shop/ bfu_2.106.01_bfu-Sicherheitsdossier\%20Nr.\%2010\%20\%E2\%80\%93\% 20Unfallforschung\%20Sport.pdf: Swiss Council for Accident Prevention; 2012

50. Shankar A, Williams K, Ryan M: Trampoline-related injury in children. Pediatr Emerg Care 2006, 22(9):644-646.

51. Levine D: All-terrain vehicle, trampoline and scooter injuries and their prevention in children. Curr Opin Pediatr 2006, 18(3):260-265.

\section{Submit your next manuscript to BioMed Central and take full advantage of:}

- Convenient online submission

- Thorough peer review

- No space constraints or color figure charges

- Immediate publication on acceptance

- Inclusion in PubMed, CAS, Scopus and Google Scholar

- Research which is freely available for redistribution 